\title{
CONSERVAÇÃO PÓS-COLHEITA DE ABACAXI 'PÉROLA' COLHIDO NO ESTÁDIO DE MATURAÇÃO “PINTADO” ASSOCIANDO-SE REFRIGERAÇÃO E ATMOSFERA MODIFICADA $^{1}$
}

\author{
ROSILENE FERREIRA SOUTO ${ }^{2}$, JOSÉ FERNANDO DURIGAN³, BIANCA SARZI DE SOUZA4 ${ }^{4}$ JULIANA DONADON ${ }^{5}$, \\ JOÃO LUIZ PALMA MENEGUCCI ${ }^{6}$
}

\begin{abstract}
RESUMO-Estudou-se a manutenção da qualidade do abacaxi 'Pérola', utilizando-se de refrigeração e atmosfera modificada. Os frutos foram armazenados em ambiente com controle de temperatura a $8^{\circ} \mathrm{C}$ e $90 \% \mathrm{UR}$, durante 17 dias, quando foram transferidos para condição de ambiente $\left(25^{\circ} \mathrm{C}, 75-80 \% \mathrm{UR}\right)$. Eles foram avaliados na recepção, caracterizando-os, após 5; 9; 13 e 17 dias sob refrigeração, e depois de transferidos para as condições de ambiente, aos 21; 25 e 29 dias. O delineamento experimental utilizado foi o inteiramente casualizado, em esquema fatorial (6 x 8), tendo-se seis tratamentos (testemunha, duas ceras e três filmes plásticos) e oito épocas de avaliação. Os frutos foram avaliados quanto à coloração, ocorrência de podridões e de escurecimento interno, e a polpa avaliada quanto ao pH e aos teores de sólidos solúveis totais (SST), acidez total titulável (ATT), ácido ascórbico e açúcares solúveis, totais e redutores. Durante o armazenamento, observaram-se o amarelecimento dos frutos, o aumento no pH, na relação SST/ ATT, e nos teores de açúcares solúveis, totais e redutores, que foram maiores após a transferência dos frutos para o ambiente. Os sintomas de injúria por chilling aumentaram com o tempo de armazenamento. Os tratamentos que modificam a atmosfera (embalagens e ceras) não influenciam significativamente nos principais atributos de qualidade do abacaxi 'Pérola', mas o uso de embalagem com PEBD e PVC atrasou o aparecimento de sintomas de escurecimento interno após a transferência dos frutos para a condição ambiente. Os frutos sem embalagem e os tratados com cera mostraram-se mais sensíveis à injúria por chilling, que se manifestou aos quatro dias após a remoção para o ambiente. A embalagem em PEBD e PVC retardou o aparecimento dos primeiros sintomas, em quatro dias.
\end{abstract}

Termos para indexação: Ananas comosus (L.) Merrill, armazenamento, chilling, friagem

\section{POSTHARVEST CONSERVATION OF 'PEROLA' PINEAPPLE FRUITS HARVESTED IN COLORED STAGE UNDER REFRIGERATED AND MODIFIED ATMOSPHERE}

\begin{abstract}
This work was conducted to evaluate the effect of refrigerated and modified atmosphere storage conditions on the quality of 'Perola' pineapple fruits. The fruits were kept under refrigerated storage conditions at $8^{\circ} \mathrm{C}$ and $90 \% \mathrm{RH}$ for 17 days, when they were transferred to environmental conditions $\left(25^{\circ} \mathrm{C}, 75-80 \% \mathrm{RH}\right)$. The evaluations were carried out during the reception and after 5, 9, 13, 17, 21, 25 and 29 days. The experimental design was completely randomized in a factorial scheme (6x8), with six treatments (control, two waxes, and three plastic film) and eight evaluation times. The evaluated parameters were: color, rot, internal browning, $\mathrm{pH}$, contents of total soluble solids (TTS), total titratable acidity -(TTA), ascorbic acid, and soluble and reducing sugars. During the storage were observed:that fruits yellowish, and increase in $\mathrm{pH}, \mathrm{TSS} / \mathrm{TTA}$ ratio, and sugars. There was a direct correspondence between the chilling occurrence and storage time. The chilling symptoms begins four days after the fruits were removed to environmental conditions, and was higher in the unpacked and waxed fruits. The PEID and PVC films delay the chilling symptoms.
\end{abstract}

Index terms: Ananas comosus (L.) Merrill, storage, chilling

\section{INTRODUÇÃO}

O Brasil é o terceiro maior produtor de abacaxi, sendo superado apenas pela Tailândia e Filipinas (FAO, 2003). A cultivar Smooth Cayenne é a mais conhecida e cultivada mundialmente, dada sua qualidade e aceitação comercial, mas a 'Pérola' já foi e continua sendo considerada a principal variedade cultivada no Brasil (Giacomelli, 1982; Reinhardt \& Souza, 2000). Estas cultivares lideram o mercado brasileiro, sendo a preferência nacional deferente de acordo com a região consumidora (Gonçalves e Carvalho, 2000). A cultivar 'Pérola' é muito apreciada no mercado interno graças a sua polpa suculenta e saborosa, considerada insuperável para o consumo ao natural, fazendo com que os frutos tenham grande potencial de comercialização internacional, pois também são muito apreciados no Mercosul e Europa.

A melhor conservação da qualidade dos frutos pós-colheita é necessária para impulsionar o agronegócio do abacaxi brasileiro, seja pela possibilidade de abastecimento das mais diferentes regiões do País, seja para incrementar as exportações de frutas in natura. As condições ambientais desejadas para tal finalidade podem ser obtidas mediante o controle da temperatura, umidade relativa e composição da atmosfera. O prolongamento da vida útil do abacaxi, usando-se frio, baseiase na regulação dos processos fisiológicos e bioquímicos (Abreu et al., 1998), com a manutenção de sua qualidade durante o transporte e a estocagem, minimizando-se a respiração, a produção e a ação do etileno e a perda de água, e retardando-se a maturação e a senescência (Salunkhe e Desai, 1984). Temperaturas adequadas devem ser utilizadas para evitar a ocorrência de injúria por "chilling" ou friagem, que se manifesta pelo escurecimento interno da polpa.

A utilização de embalagens mantém a qualidade durante o armazenamento e leva a modificação na atmosfera, o que retarda a respiração, o amadurecimento, a senescência, a perda de clorofila, a perda de umidade, o escurecimento enzimático e, conseqüentemente, os prejuízos na qualidade devido ao processamento (Sarantópoulos, 1999). A técnica da atmosfera modificada utiliza-se da embalagem em filme plástico e da aplicação de ceras, com conseqüente modificação da concentração dos gases no interior dos tecidos do vegetal, devido à respiração. $\mathrm{O}$ ideal é que a película utilizada reduza a concentração de $\mathrm{O}_{2}$ a níveis suficientemente baixos para retardar a respiração, sem permitir a

\footnotetext{
${ }^{1}$ (Trabalho 105/2003). Recebido: 04/09/2003. Aceito para publicação: 13/04/2004. Parte da Tese de Doutorado da primeira autora. Financiado pela FAPESP.

${ }^{2}$ Eng. Agrônoma, Fiscal Federal, DFA-GO, Goiânia-GO. Praça Cívica, 100. Centro, Goiânia-GO - (62)221-7268 - rosilenef@agricultura.gov.br.

${ }^{3}$ Prof. Titular do Departamento de Tecnologia da FCAV/Unesp, Jaboticabal. Via de acesso Prof. Paulo Donato Castellane, s/n, 14.884-900, Jaboticabal-SP. Telefone (16)3209-2675 - iduri@fcav.unesp.br.

${ }^{4}$ Eng. Agrônoma, aluna de Doutorado do Departamento de Tecnologia da FCAV/Unesp, Jaboticabal. Via de acesso Prof. Paulo Donato Castellane, s/n, 14.884-900, Jaboticabal-SP. Telefone (16)3209-2675, biasarzi@fcav.unesp.br.

${ }^{5}$ Eng. Agrônoma aluna de Mestrado do Departamento de Tecnologia da FCAV/UNESP, Jaboticabal. Via de acesso Prof. Paulo Donato Castellane, s/n, 14.884-900, Jaboticabal-SP. Telefone (16)3209-2675. julianadonadon@yahoo.com.br.

${ }^{6}$ Eng. Agrônomo, D.Sc. Pesquisador Embrapa Mandioca e Fruticultura, Escritório de Negócios de Goiânia. Rod. BR153. km 04. Telefone: (62)202-6000. meneguci@cnpmf.embrapa.br.
} 
respiração anaeróbia, e impedir o acúmulo de $\mathrm{CO}_{2}$ em níveis que provoquem distúrbios fisiológicos. A modificação na atmosfera também retarda a perda de clorofila e de umidade, e o escurecimento enzimático (Sarantópoulus, 1999).

O uso do filme de cloreto de polivinila (PVC), esticável, devido a sua grande aderência à fruta, impede a formação de bolsas de ar e, por se tratar de película delgada e microporosa, restringe a quantidade de oxigênio absorvida do ar. Isto torna a respiração mais lenta, retarda os processos fisiológicos, sem gerar condições anaeróbias, e evita a perda de umidade pela transpiração (Bleinroth, 1987).

Em estudo de Pico e Pólit (2000), a cera foi utilizada para proteger frutos do abacaxizeiro 'Champaka' da injúria causada por armazenamento a $8^{\circ} \mathrm{C}$, mas a evolução da coloração foi inibida pela sua aplicação. Sacos plásticos perfurados não influenciaram no desenvolvimento da cor externa dos frutos, mas não foram eficientes para diminuir o escurecimento interno. A combinação dos mesmos com a cera protegeu contra o escurecimento interno, retendo a perda de vitamina $\mathrm{C}$ e diminuindo a perda de massa fresca. Estes tratamentos não têm efeito sobre a integridade da coroa e os teores de sólidos solúveis totais e de acidez titulável.

O objetivo deste trabalho foi determinar o efeito do uso do armazenamento refrigerado e sua associação com a modificação da atmosfera na conservação pós-colheita do abacaxi 'Pérola'.

\section{MATERIAL E MÉTODOS}

Os frutos da cultivar Pérola foram colhidos manualmente, em Frutal-MG, no estádio de maturação "pintado", caracterizado por apresentar os frutilhos com o centro amarelo, apresentando peso médio de $1.120,4 \mathrm{~g}$, diâmetro de $11,1 \mathrm{~cm}$, comprimento do fruto e coroa de 37,9 $\mathrm{cm}$ e coroa com $23,3 \mathrm{~cm}$ e 132, $9 \mathrm{~g}$. Foram cuidadosamente transportados para o laboratório de Tecnologia dos Produtos Agrícolas da FCAV, Jaboticabal, UNESP, onde foram novamente selecionados. Esses frutos foram lavados e imersos em fungicida Sportak a $1.000 \mathrm{ppm}$, a $10^{\circ} \mathrm{C}$, por 20 minutos. Após esse tratamento, os frutos foram transferidos para ambiente a $25^{\circ} \mathrm{C}$ e $75-80 \%$ UR, por 12 horas.

Depois de divididos aleatoriamente em seis grupos, os frutos foram submetidos aos tratamentos: testemunha, sem embalagem; embalagem em filme de polietileno de baixa densidade, com espessura de 0,05 mm e com vácuo parcial (PEBD-CV); embalagem em filme de PEBD com espessura de $0,05 \mathrm{~mm}$ (PEDB); embalagem em filme de cloreto de polivinila esticável e espessura de $0,017 \mathrm{~mm}$ (PVC); imersão em cera "Sta Fresh" da FMC, diluída com água, na proporção 1:1 (v:v) (STA FRESH); e imersão em cera "Sparcitrus" da Spartan do Brasil, diluída com água, na proporção 1:1 (v:v) (SPARCITRUS).

Estes frutos foram mantidos sob refrigeração ( $8^{\circ} \mathrm{C}$ e $90 \%$ UR) durante 17 dias, quando foram transferidos para condição de ambiente ( $\left.25^{\circ} \mathrm{C}, 75-80 \% \mathrm{UR}\right)$. Os frutos foram avaliados no início (0 dia) e após 5; 9; 13 e 17 dias (armazenamento refrigerado) e aos 21; 25 e 29 dias (armazenamento no ambiente). Essas avaliações compreenderam observação da ocorrência de podridões na casca ou na polpa, bem como a caracterização da polpa, quanto à coloração, ocorrência de escurecimento interno, $\mathrm{pH}$ e teores de sólidos solúveis totais, acidez total titulável, ácido ascórbico e de açúcares solúveis totais e redutores.

A coloração da polpa foi avaliada através de reflectometria, utilizando-se de um aparelho Minolta Chroma Meter CR-200b, que expressa esse parâmetro pela luminosidade (L), cromaticidade e ângulo hue ou de cor (Wolf et al., 1997). Essas avaliações permitiram estabelecer relações entre a coloração visual (notas) e a instrumental (reflectometria). $\mathrm{O}$ índice de escurecimento interno (EI) foi determinado, em cada fruto, mediante a multiplicação da porcentagem da área afetada pela intensidade do escurecimento interno (EI) de acordo com a metodologia proposta por Gonçalves (1998).

A polpa dos frutos também foi avaliada quanto ao $\mathrm{pH}$ (AOAC, 1997) e aos teores de sólidos solúveis totais, acidez total titulável, ácido ascórbico (AOAC, 1997), de açúcares solúveis totais (Dubois et al., 1956) e redutores (Miller, 1959).

O delineamento experimental utilizado foi o inteiramente casualizado, em esquema fatorial (6 x 8), tendo-se seis tratamentos (testemunha, duas ceras e três filmes plásticos) e oito épocas de avaliação. Os dados obtidos foram submetidos à análise de variância (ANOVA), e as médias foram comparadas pelo teste de Tukey, a $5 \%$ de probabilidade.

\section{RESULTADOS E DISCUSSÃO}

A polpa não teve a luminosidade (L), assim como o ângulo de cor ou hue $\left(\mathrm{h}^{\circ}\right)$ significativamente afetados pelos tratamentos, mas mostrou tendência de se tornar mais clara durante o período de armazenamento até o $29^{\circ}$ dia, pois a luminosidade aumentou de 63,70 para 65,90, assim como mais amarelada, com o $\mathrm{h}^{\circ}$ crescendo de 101,76 para 102,24. A cromaticidade da polpa também não foi afetada pelos tratamentos, mas aumentou linearmente $\left(Y=15,430+0,1432 X, R^{2}=0,75\right) \mathrm{com}$ o decorrer do armazenamento, passando de 14,66 para 19,21, indicando aumento na quantidade de pigmentos (dados não apresentados). Os resultados deste trabalho indicam que a coloração da polpa tornou-se mais amarelada e brilhante durante o período de armazenamento, o que também foi observado visualmente. Sarzi (2002) também observou que a coloração da polpa de abacaxi 'Perola' minimamente processado tornouse amarelo-clara durante o armazenamento refrigerado, com a cromaticidade passando de 14,0 para 15,0, em 12 dias. Pico e Pólit (2002) não constatram mudança na translucidez da polpa de abacaxis tratados com ceras e armazenados a $8^{\circ} \mathrm{C}$, mas relataram efeito semelhante ao observado neste trabalho, quando os frutos foram embalados em sacos plásticos perfurados, que foi atribuído ao processo de maturação e senescência.

Neste trabalho, não se observou a ocorrência de podridões na casca ou na polpa dos frutos, durante o período experimental. Somente no $29^{\circ}$ dia ocorreu crescimento fúngico nos frutos embalados em PEBD, favorecido pelo acúmulo de água.

O teor de sólidos solúveis totais (SST) da polpa do abacaxi, cujo valor médio foi de $14,05 \pm 0,89^{\circ} \mathrm{Brix}$ (Tabela 1 ), sendo maior do que

TABELA 1-Teor de sólidos solúveis totais ( ${ }^{\circ}$ Brix) na polpa de frutos de abacaxis 'Pérola', submetidos a diferentes embalagens e ceras, e armazenados a $8^{\circ} \mathrm{C}$, até o $17^{\circ}$ dia, antes de serem levados a condição ambiente $\left(25^{\circ} \mathrm{C}\right.$ UR) por mais 12 dias. Jaboticabal, 2003.

\begin{tabular}{|c|c|c|c|c|c|c|c|c|c|}
\hline \multirow[b]{2}{*}{ TRATAMENTO } & \multicolumn{9}{|c|}{ ARMAZENAMENTO (DIAS) } \\
\hline & 0 & 5 & 9 & 13 & 17 & 21 & 25 & 29 & Média \\
\hline PEBD-CV & 14,25 & 13,55 & 13,35 & 14,75 & 13,90 & 14,45 & 13,55 & 12,95 & $13,84 \mathrm{a}$ \\
\hline PVC & 14,25 & 12,95 & 13,55 & 13,75 & 13,85 & 13,10 & 13,60 & 14,25 & $13,66 a$ \\
\hline STA FRESH & 14,25 & 13,90 & 13,70 & 13,35 & 13,95 & 14,60 & 14,30 & 15,30 & $14,16 \mathrm{a}$ \\
\hline SPARCITRUS & 14,25 & 13,50 & 14,65 & 14,65 & 14,00 & 13,80 & 14,15 & 14,60 & $14,20 \mathrm{a}$ \\
\hline
\end{tabular}

$\mathrm{CV}=6,35 \%$; desvio-padrão $=0,89$

Médias seguidas de letras iguais, minúscula na coluna e maiúscula na linha, não diferem entre si, pelo teste de Tukey $(\mathrm{P}<0,05)$.

Tratamentos- TESTEMUNHA (sem tratamento); PEDB-CV (filme de PEDB c/ vácuo parcial); PEDB (filme de PEDB); PVC (cloreto de polivinila); STA FRESH e SPARCITRUS (ceras) 
TABELA 2 - Acidez total titulável (g.ácido cítrico. $100 \mathrm{~g}^{-1}$ ) na polpa de frutos de abacaxis 'Pérola', submetidos a diferentes embalagens e ceras, e armazenados a $8^{\circ} \mathrm{C}$ por 17 dias, e à condição ambiente $\left(25^{\circ} \mathrm{C}\right.$ UR) por mais 12 dias. Jaboticabal, 2003.

\begin{tabular}{l|c|c|c|c|c|c|c|c}
\hline & \multicolumn{7}{c}{ ARMAZENAMENTO (DIA) } \\
\cline { 2 - 8 } TRATAMENTO & 0 & 5 & 9 & 13 & 17 & 21 & 25 & 29 \\
\hline TESTEMUNHA & $0,41 \mathrm{aAB}$ & $0,62 \mathrm{aAB}$ & $0,68 \mathrm{aA}$ & $0,74 \mathrm{aA}$ & $0,83 \mathrm{aA}$ & $0,76 \mathrm{abcA}$ & $0,80 \mathrm{aA}$ \\
PEBD-CV & $0,41 \mathrm{aD}$ & $0,61 \mathrm{aBCD}$ & $0,68 \mathrm{aABC}$ & $0,80 \mathrm{aAB}$ & $0,87 \mathrm{aA}$ & $0,64 \mathrm{bcBC}$ & $0,61 \mathrm{abBCD}$ & $0,70 \mathrm{aA}$ \\
PEBD & $0,41 \mathrm{aC}$ & $0,60 \mathrm{aBC}$ & $0,66 \mathrm{aAB}$ & $0,73 \mathrm{aAB}$ & $0,82 \mathrm{aA}$ & $0,57 \mathrm{cBC}$ & $0,57 \mathrm{bBC}$ & $0,62 \mathrm{abABC}$ \\
PVC & $0,41 \mathrm{aC}$ & $0,64 \mathrm{aB}$ & $0,67 \mathrm{aAB}$ & $0,70 \mathrm{aAB}$ & $0,80 \mathrm{aAB}$ & $0,89 \mathrm{aA}$ & $0,75 \mathrm{abAB}$ & $0,64 \mathrm{abB}$ \\
STA FRESH & $0,41 \mathrm{aD}$ & $0,53 \mathrm{aCD}$ & $0,59 \mathrm{aBCD}$ & $0,80 \mathrm{aAB}$ & $0,84 \mathrm{aA}$ & $0,76 \mathrm{abcAB}$ & $0,80 \mathrm{aAB}$ & $0,73 \mathrm{aABC}$ \\
SPARCITRUS & $0,41 \mathrm{aD}$ & $0,57 \mathrm{aBCD}$ & $0,56 \mathrm{aCD}$ & $0,60 \mathrm{aBCD}$ & $0,83 \mathrm{aA}$ & $0,79 \mathrm{abAB}$ & $0,62 \mathrm{abABCD}$ & $0,69 \mathrm{abABC}$ \\
\hline
\end{tabular}

$\mathrm{CV}=10,36 \%$; desvio-padrão $=0,06$

Tratamentos- TESTEMUNHA (sem tratamento); PEDB-CV (filme de PEDB c/ vácuo parcial); PEDB (filme de PEDB); PVC (cloreto de polivinila); STA FRESH e SPARCITRUS (ceras).

Médias seguidas de, pelo menos, uma letra igual, minúscula nas colunas e maiúscula nas linhas, não diferem entre si, pelo teste de Tukey (P<0,05).

o relatado por Sarzi (2002), não foi significativamente alterado pelo tempo de armazenamento ou pelo uso das diferentes embalagens, o que também foi relatado por Pico e Pólit (2000). No entanto, Botrel e Carvalho (1993) observaram decréscimo nos teores de SST, quando trabalharam com frutos de abacaxi 'Smooth Cayenne'. Botrel (1991) encontrou valores maiores em frutos mantidos sob refrigeração que nos não refrigerados. Silva (1980) observou aumento no SST de $12,8^{\circ}$ Brix para $14,0^{\circ}$ Brix, em condições de refrigeração, e para $13,5^{\circ}$ Brix quando os frutos do 'Pérola' foram mantidos em condições de ambiente. Esse autor também relatou que o fruto da cv. Pérola apresenta teores de sólidos solúveis totais maiores e menos variáveis que os da cv. Smooth Cayenne.

A acidez total titulável (ATT) da polpa aumentou durante o período a $8^{\circ} \mathrm{C}$ e diminuiu quando os frutos foram levados a condições de ambiente (Tabela 2). Não houve efeito das embalagens e ceras enquanto os frutos foram mantidos a $8^{\circ} \mathrm{C}$, mas a ATT reduziu-se nos frutos embalados em PEDB-CV e PVC quando foram levados ao ambiente $\left(25^{\circ} \mathrm{C}\right.$ e 75-80\% UR), como efeito da modificação na atmosfera.

AATT em frutos da 'Smooth Cayenne', no estádio de maturação 2 , aumentou durante o armazenamento refrigerado e decresceu em frutos colhidos no estádio 3, mais maduros (Thé et al., 2001). Silva (1980) armazenou frutos a $12^{\circ} \mathrm{C}$ e $80 \%$ UR e observou aumento da ATT nos frutos 'Smooth Cayenne' até o $25^{\circ}$ dia, que se reduziu no final do experimento, a qual não aconteceu nos frutos 'Perola'. Sarzi (2002) também observou aumento na ATT durante o período de armazenamento refrigerado, e quanto maior a temperatura, menores foram os valores, indicando senescência mais rápida. No entanto, Botrel e Carvalho (1993) observaram em abacaxi 'Smooth Cayenne' que os valores da ATT apresentaram uma tendência decrescente durante o período sob refrigeração, enquanto Pico e Pólit (2000) não detectaram variações para frutos acondicionados em sacos de polietileno ou encerados.

A relação SST/ATT (Tabela 3) diminuiu durante o armazenamento a $8^{\circ} \mathrm{C}$ e aumentou com a remoção dos frutos para a condição de ambiente $\left(25^{\circ} \mathrm{C}\right.$ e $75-80 \%$ UR). Esses valores variaram de 34,55 na colheita, para 22,32 no $29^{\circ}$ dia, com os tratamentos não mostrando influência significativa. O valor médio encontrado, 22,37 \pm 3,92 , é semelhante ao relatado por Sarzi (2002), que considerou esses frutos doces. Silva (1980), Botrel e Carvalho (1993) e Gorgatti Neto et al. (1996) também relataram decréscimos nessa relação, tanto em frutos armazenados em condições de ambiente $\left(25^{\circ} \mathrm{C}\right.$ e $75-80 \%$ UR), como a $12^{\circ} \mathrm{C}$. Thé et al. (2001) também observaram que frutos armazenados sob refrigeração, por 20 dias, apresentaram valores mais baixos da relação SST/ATT que os mantidos em condições de ambiente $\left(25^{\circ} \mathrm{C}\right.$ e $75-80 \%$ UR).

$\mathrm{O}$ valor do $\mathrm{pH}$ da polpa reduziu durante o armazenamento a $8^{\circ} \mathrm{C}$, refletindo o aumento da ATT, e voltou a aumentar, quando os frutos foram levados a condições de ambiente $\left(25^{\circ} \mathrm{C}\right.$ e $\left.75-80 \% \mathrm{UR}\right)$, com maior intensidade nos frutos que foram protegidos com filmes plásticos (Tabela 4). O valor médio encontrado foi de 3,68 $\pm 0,08$, que é semelhante ao valor relatado por Gorgati Neto et al. (1996) e Sarzi (2002). Silva (1980) encontrou, em frutos mantidos ao ambiente e sob refrigeração, aumento no $\mathrm{pH}$ até o $18^{\circ}$ dia, que depois diminuiu.

A quantidade de açúcares solúveis totais e redutores diminuiu durante o período de armazenamento sob refrigeração, mas aumentou quando os frutos foram levados às condições de ambiente $\left(25^{\circ} \mathrm{C}\right.$ e 75 $80 \%$ UR), sem que os tratamentos influenciassem nesses valores (Tabela 5, Figura 1). Resultados similares foram obtidos por Thé et al. (2001) com frutos 'Smooth Cayenne'.

O teor de ácido ascórbico na polpa dos frutos não sofreu influência das embalagens, mas durante o tempo de armazenamento a $8^{\circ} \mathrm{C}$ aumentou, diminuindo quando os frutos foram levados a condição ambiente $\left(25^{\circ} \mathrm{C}\right.$ e $75-80 \%$ UR). Essa redução ocorreu com maior intensidade nos frutos protegidos com filme plástico (Tabela 6). Pico e Pólit (2000) concluíram que a utilização de ceras permitiu maior retenção no conteúdo de vitamina $\mathrm{C}$, o que não foi observado nesse trabalho. Botrel (1991) verificou que os frutos maiores, cujo teor de ácido ascórbico era menor, foram os mais sensíveis ao escurecimento interno, quando armazenados sob refrigeração. Sarzi (2002) também observou que, quanto mais alta a temperatura de armazenamento, menor é a conservação do

TABELA 3- Relação entre SST/ATT na polpa de frutos de abacaxis 'Pérola', submetidos a diferentes embalagens e ceras, e armazenados a $8^{\circ} \mathrm{C}$, até o $17^{\circ}$ dia, e à condição ambiente ( $\left(25^{\circ} \mathrm{C}\right.$ UR) por mais 12 dias. Jaboticabal, 2003.

\begin{tabular}{l|c|c|c|c|c|c|c|c|c}
\hline \multirow{2}{*}{ TRATAMENTO } & \multicolumn{10}{c}{ ARMAZENAMENTO (DIAS) } \\
\cline { 2 - 9 } & 0 & 5 & 9 & 13 & 17 & 21 & 25 & 29 & Média \\
\hline TESTEMUNHA & 34,55 & 22,61 & 19,75 & 18,95 & 18,32 & 18,86 & 19,24 & 22,18 \\
PEBD-CV & 34,55 & 25,16 & 19,39 & 18,29 & 15,88 & 22,39 & 22,99 & 25,89 & $23,06 \mathrm{a}$ \\
PEBD & 34,55 & 24,89 & 20,89 & 20,08 & 16,40 & 23,98 & 26,00 & 21,81 & $23,57 \mathrm{a}$ \\
PVC & 34,55 & 19,86 & 19,98 & 19,41 & 17,30 & 14,65 & 17,94 & 22,11 & $20,72 \mathrm{a}$ \\
STA FRESH & 34,55 & 26,09 & 23,11 & 16,77 & 16,60 & 19,04 & 17,67 & 20,86 & $21,83 \mathrm{a}$ \\
SPARCITRUS & 34,55 & 23,21 & 25,71 & 24,17 & 16,77 & 17,30 & 22,75 & 21,10 & $23,19 \mathrm{a}$ \\
\hline Média & $34,55 \mathrm{~A}$ & $23,64 \mathrm{~B}$ & $21,47 \mathrm{BC}$ & $19,61 \mathrm{BC}$ & $16,87 \mathrm{C}$ & $19,37 \mathrm{BC}$ & $21,10 \mathrm{BC}$ & $22,32 \mathrm{~B}$ \\
\hline
\end{tabular}

$\mathrm{CV}=17,35 \%$; desvio-padrão=3,92

Médias seguidas de letras iguais, minúscula na coluna e maiúscula na linha, não diferem entre si, pelo teste de Tukey $(\mathrm{P}<0,05)$.

Tratamentos- TESTEMUNHA (sem tratamento); PEDB-CV (filme de PEDB c/ vácuo parcial); PEDB (filme de PEDB); PVC (cloreto de polivinila); STA FRESH e SPARCITRUS (ceras) 
TABELA 4 - pH da polpa de frutos de abacaxis 'Pérola' submetidos a diferentes embalagens e ceras, e armazenados a $8^{\circ} \mathrm{C}$ por 17 dias, e à condição ambiente $\left(25^{\circ} \mathrm{C} \mathrm{UR}\right)$ por mais 12 dias. Jaboticabal, 2003.

\begin{tabular}{l|c|c|c|c|c|c|c|c}
\hline & \multicolumn{7}{c}{ ARMAZENAMENTO (DIA) } \\
\cline { 2 - 8 } TRATAMENTO & 0 & 5 & 9 & 13 & 17 & 21 & 25 & 29 \\
\hline TESTEMUNHA & $3,97 \mathrm{aA}$ & $3,56 \mathrm{aB}$ & $3,67 \mathrm{aB}$ & $3,60 \mathrm{aB}$ & $3,50 \mathrm{aB}$ & $3,74 \mathrm{aAB}$ & $3,63 \mathrm{abB}$ & $3,76 \mathrm{abcAB}$ \\
PEBD-CV & $3,97 \mathrm{aA}$ & $3,70 \mathrm{aABC}$ & $3,64 \mathrm{aBC}$ & $3,53 \mathrm{aC}$ & $3,43 \mathrm{aC}$ & $3,83 \mathrm{aAB}$ & $3,88 \mathrm{aAB}$ & $3,91 \mathrm{aAB}$ \\
PEBD & $3,97 \mathrm{aA}$ & $3,62 \mathrm{aBCD}$ & $3,55 \mathrm{aCD}$ & $3,52 \mathrm{aD}$ & $3,55 \mathrm{aCD}$ & $3,83 \mathrm{aAB}$ & $3,87 \mathrm{aAB}$ & $3,82 \mathrm{abABC}$ \\
PVC & $3,97 \mathrm{aA}$ & $3,56 \mathrm{aB}$ & $3,60 \mathrm{aB}$ & $3,46 \mathrm{aB}$ & $3,52 \mathrm{aB}$ & $3,67 \mathrm{aB}$ & $3,59 \mathrm{bB}$ & $3,64 \mathrm{bcB}$ \\
STA FRESH & $3,97 \mathrm{aA}$ & $3,66 \mathrm{aAB}$ & $3,67 \mathrm{aB}$ & $3,46 \mathrm{aB}$ & $3,51 \mathrm{aB}$ & $3,73 \mathrm{aB}$ & $3,57 \mathrm{bB}$ & $3,53 \mathrm{cB}$ \\
SPARCITRUS & $3,97 \mathrm{aA}$ & $3,61 \mathrm{aB}$ & $3,74 \mathrm{aB}$ & $3,55 \mathrm{aB}$ & $3,58 \mathrm{aB}$ & $3,67 \mathrm{aAB}$ & $3,70 \mathrm{abB}$ & $3,59 \mathrm{bcB}$ \\
\hline
\end{tabular}

$\mathrm{CV}=2,33 \%$; desvio-padrão $=0,08$

Tratamentos- TESTEMUNHA (sem tratamento); PEDB-CV (filme de PEDB c/ vácuo parcial); PEDB (filme de PEDB); PVC (cloreto de polivinila); STA FRESH e SPARCITRUS (ceras)

Médias seguidas de, pelo menos, uma letra igual, minúscula na coluna e maiúscula na linha, não diferem entre si, pelo teste de Tukey $(\mathrm{P}<0,05)$.

TABELA 5 - Açúcares solúveis totais (g.glicose. $100 \mathrm{~g}^{-1}$ ) na polpa de frutos de abacaxis 'Pérola' submetidos a diferentes embalagens e ceras, e armazenados a $8^{\circ} \mathrm{C}$ por 17 dias, e à condição ambiente $\left(25^{\circ} \mathrm{C}\right.$ UR) por mais 12 dias. Jaboticabal, 2003.

\begin{tabular}{|c|c|c|c|c|c|c|c|c|c|}
\hline \multirow[b]{2}{*}{ TRATAMENTO } & \multicolumn{9}{|c|}{ ARMAZENAMENTO (DIA) } \\
\hline & 0 & 5 & 9 & 13 & 17 & 21 & 25 & 29 & Média \\
\hline TESTEMUNHA & 12,86 & 12,30 & 10,02 & 10,63 & 10,54 & 11,01 & 12,21 & 12,49 & $11,50 \mathrm{a}$ \\
\hline PEBD-CV & 12,86 & 12,55 & 10,33 & 10,37 & 9,78 & 11,98 & 10,42 & 9,86 & $11,02 \mathrm{a}$ \\
\hline PEBD & 12,86 & 11,99 & 10,58 & 11,20 & 9,94 & 11,31 & 11,81 & 10,26 & $11,24 \mathrm{a}$ \\
\hline PVC & 12,86 & 11,73 & 10,36 & 9,14 & 10,97 & 10,47 & 10,77 & 11,18 & $10,93 a$ \\
\hline STA FRESH & 12,86 & 13,37 & 10,32 & 9,65 & 10,52 & 11,32 & 11,22 & 11,92 & $11,39 a$ \\
\hline SPARCITRUS & 12,86 & 11,59 & 10,92 & 10,90 & 10,55 & 12,51 & 10,86 & 11,79 & $11,50 \mathrm{a}$ \\
\hline Média & $12,86 \mathrm{~A}$ & $12,25 \mathrm{AB}$ & $10,42 \mathrm{C}$ & $10,31 \mathrm{C}$ & $10,38 \mathrm{C}$ & $11,43 \mathrm{BC}$ & $11,21 \mathrm{BC}$ & $11,25 \mathrm{BC}$ & \\
\hline
\end{tabular}

Tratamentos- TESTEMUNHA (sem tratamento); PEDB-CV (filme de PEDB c/ vácuo parcial); PEDB (filme de PEDB); PVC (cloreto de polivinila); STA FRESH e SPARCITRUS (ceras)

Médias seguidas de, pelo menos, uma letra igual minúscula na coluna e maiúscula na linha, não diferem entre si, pelo teste de Tukey $(\mathrm{P}<0,05)$.

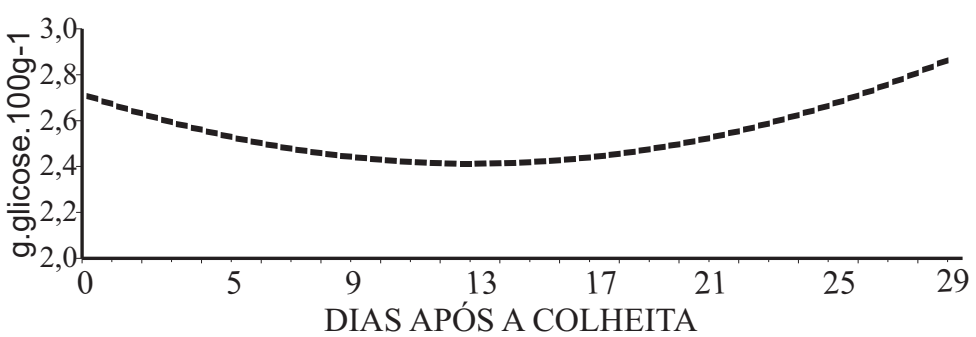

FIGURA 1 - Evolução no conteúdo de açúcares redutores na polpa de frutos de abacaxis 'Pérola' submetidos a diferentes embalagens e ceras, e armazenados a $8^{\circ} \mathrm{C}$ por 17 dias, e à condição ambiente $\left(25^{\circ} \mathrm{C} \mathrm{UR}\right)$ por mais 12 dias. Jaboticabal, 2003.

teor de ácido ascórbico, e atribuiu essa maior perda ao aumento na atividade enzimática.

O escurecimento interno (EI), manifestado após a transferência dos frutos da condição refrigerada $\left(8^{\circ} \mathrm{C}\right)$ para o ambiente $\left(25^{\circ} \mathrm{Ce} 75-80 \%\right.$ UR), só foi detectado no $4^{\circ}$ dia após essa transferência,ou seja, no $21^{\circ}$ dia. Nessa data, apenas os frutos-testemunha $(1,73 \%)$ e os que foram tratados com cera $(13,48 \%$ e $7,53 \%)$, para Sta Fresh e Sparcitrus, respectivamente, apresentaram esse sintoma de injúria pelo frio ou chilling (Figura 2). Após 8 dias e 12 dias sob condições de ambiente $\left(25^{\circ} \mathrm{C}\right.$ e $\left.75-80 \% \mathrm{UR}\right)$, todos os frutos-apresentaram sintomas de escurecimento interno, mas com maior intensidade nos frutostestemunha. Os filmes plásticos retardaram a evolução desse escurecimento, dos quais o saco de PEBD sem vácuo foi o mais eficiente. Pico e Pólit (2000) também observaram que frutos sem

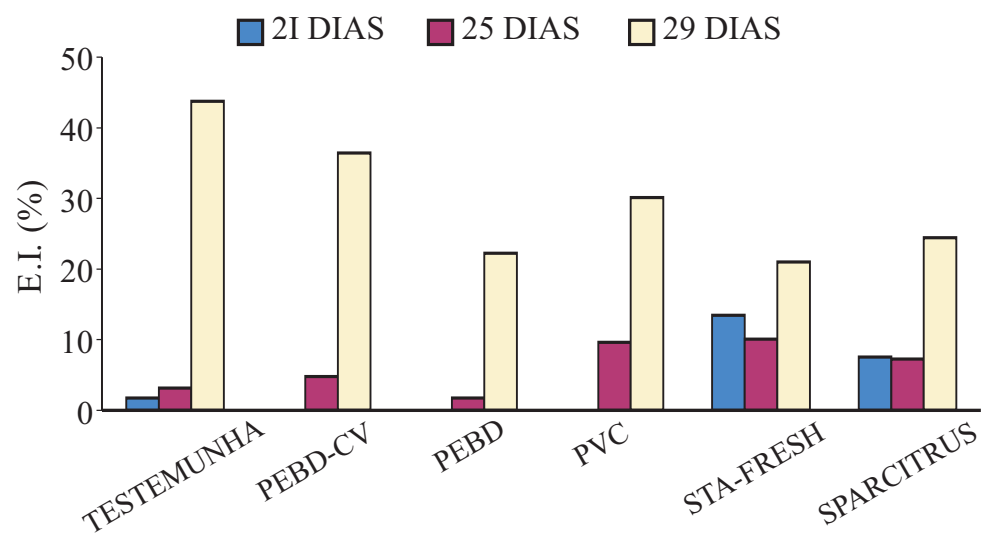

TRATAMENTOS

FIGURA 2 - Índice de escurecimento interno (EI) em frutos de abacaxi 'Pérola' submetidos a diferentes embalagens e ceras, e armazenados a $8^{\circ} \mathrm{C}$ por 17 dias, e à condição ambiente $\left(25^{\circ} \mathrm{C}\right.$ UR) por mais 12 dias. Jaboticabal, 2003.

embalagem apresentaram maior incidência do escurecimento interno, e que a cera Tandem 552 ofereceu excelente proteção, com menor desempenho para a cera Sta-Fresh. Para esses autores, o uso de sacos plásticos perfurados não foi considerado eficiente. Abreu et al. (1998), utilizando embalagens de polietileno de $0,07 \mathrm{~mm}$, observaram redução de $68,75 \%$ no número de frutos afetados pelo EI, o que foi atribuído à redução na disponibilidade de $\mathrm{O}_{2}$, impedindo a oxidação e, conseqüentemente, o escurecimento interno, o que vem ao encontro dos resultados obtidos neste trabalho. 
TABELA 6 - Ácido ascórbico (mg. $100 \mathrm{~g}^{-1}$ ) na polpa de frutos de abacaxis 'Pérola' submetidos a diferentes embalagens e ceras, e armazenados a $8^{\circ} \mathrm{C}$ por 17 dias, e à condição ambiente $\left(25^{\circ} \mathrm{C}\right.$ UR) por mais 12 dias. Jaboticabal, 2003.

\begin{tabular}{|c|c|c|c|c|c|c|c|c|c|}
\hline \multirow[b]{2}{*}{ TRATAMENTO } & \multicolumn{9}{|c|}{ ARMAZENAMENTO (DIA) } \\
\hline & 0 & 5 & 9 & 13 & 17 & 21 & 25 & 29 & Média \\
\hline TESTEMUNHA & 18,28 & 20,90 & 25,50 & 23,38 & 27,07 & 21,39 & 23,20 & 21,18 & $22,61 \mathrm{a}$ \\
\hline PEBD-CV & 18,28 & 22,92 & 23,94 & 26,79 & 32,39 & 19,65 & 15,44 & 14,60 & $21,75 a$ \\
\hline PEBD & 18,28 & 18,08 & 20,36 & 23,43 & 28,70 & 18,66 & 16,78 & 15,99 & $20,03 a$ \\
\hline PVC & 18,28 & 24,89 & 23,72 & 23,92 & 26,46 & 32,35 & 24,85 & 18,57 & $24,13 \mathrm{a}$ \\
\hline STA FRESH & 18,28 & 19,72 & 20,03 & 29,79 & 30,30 & 22,95 & 31,41 & 21,17 & $24,20 \mathrm{a}$ \\
\hline SPARCITRUS & 18,28 & 23,15 & 21,50 & 23,59 & 32,58 & 24,14 & 17,08 & 20,80 & $22,64 a$ \\
\hline Média & $18,28 \mathrm{C}$ & $21,61 \mathrm{BC}$ & $22,51 \mathrm{BC}$ & $25,15 \mathrm{AB}$ & $29,58 \mathrm{~A}$ & $23,19 \mathrm{BC}$ & $21,46 \mathrm{BC}$ & $18,72 \mathrm{C}$ & \\
\hline
\end{tabular}

Tratamentos- TESTEMUNHA (sem tratamento); PEDB-CV (filme de PEDB c/ vácuo parcial); PEDB (filme de PEDB); PVC (cloreto de polivinila); STA FRESH e SPARCITRUS (ceras)

Médias seguidas de, pelo menos, uma letra igual, minúscula na coluna e maiúscula na linha, não diferem entre si, pelo teste de Tukey (P<0,05).

\section{CONCLUSÕES}

1) A condição de armazenamento influencia na evolução da qualidade dos frutos de abacaxi 'Pérola'. Os tratamentos utilizados não influenciaram na evolução da coloração da polpa, que se tornou mais clara e mais amarelada com o tempo.

2) Sob refrigeração, há aumento na acidez total titulavel (ATT) e no teor de ácido ascórbico, e redução na relação SST/ATT e teores de açúcares solúveis totais e redutores, ocorrendo o contrário quando os frutos são transferidos para condições ambiente.

3) Os tratamentos que modificam a atmosfera (embalagens e ceras) não influenciam significativamente nos principais atributos de qualidade do abacaxi 'Pérola', mas o uso de embalagem com PEBD e PVC atrasou o aparecimento de sintomas de escurecimento interno após a transferência dos frutos para a condição ambiente. Os tratamentos testados não impediram o aparecimento do escurecimento interno.

\section{REFERÊNCIAS BIBLIOGRÁFICAS}

ABREU, C. M. P. de; CARVALHO, V. D. de; SANTOS, D. dos S.; CHAGAS, S. de R.; COSTA, L. Efeito da embalagem de polietileno e da refrigeração no escurecimento interno, na atividade da fenilalanina amônio liase (PAL) e fenólicos durante a maturação do abacaxi cv. Smooth Cayenne. Revista Brasileira de Fruticultura, Cruz das Almas, v. 20, n.1, p. 80-86, 1998.

AOAC. Official methods of analysis of the Association of Official Analytical Chemists. 16. ed. Washington: AOAC, 1997. v.2, p.3710, 42-42, 44-43, 45-16.

BLEINROTH, E. W. Matéria-Prima. In: ITAL. Abacaxi: cultura, matériaprima, processamento e aspectos econômicos. 2. ed. Campinas: ITAL, 1987. p.133-164. (Série Frutas Tropicais, 2).

BOTREL, N. Efeito do peso do fruto no escurecimento interno e qualidade do abacaxí 'Smooth Cayenne'. 1991. 81f. Dissertação (Mestrado em Ciência dos Alimentos) - Universidade Federal de Lavras, Lavras, 1991.

BOTREL, N.; CARVALHO, V. D. Efeito do peso do fruto no escurecimento interno e qualidade do abacaxi 'Smooth cayenne'. Pesquisa Agropecuária Brasileira, Brasília, v. 28, n.9, 1055-1064, 1993.

DUBOIS, M.; GILLES, K. A.; HAMILTON, J. K.; REBER, P. A.; SMITH, F. Colorimetric method for determination of sugars and related substances. Analytical Chemistry, Washington, v.8, n.3, p.350-356, 1956.

FAO. FAOSTAT DATABASE COLLECTIONS, Disponível em: <http:// apps.fao.org/page/collections?subet=agriculture $>$. Consultado em: 08 MAIO. 2003.

GIACOMELLI, E. J. Expansão da abacaxicultura no Brasil. Campinas: Fundação Cargill, 1982. 79p.

GONÇALVES, N. B. Efeito da aplicação de cloreto de cálcio associado ao tratamento hidrotérmico sobre a composição química e suscetibilidade ao escurecimento interno do abacaxi c.v. Smooth Cayenne. 1998. 96f. Tese (Doutorado em Fitotecnia) - Universidade Federal de Lavras, Lavras, 1998.

GONÇALVES, N. B.; CARVALHO, V. D. de. Características da fruta. In: GONÇALVES, N. B. (Org.). Abacaxi pós-colheita. Brasília: Ministério da Agricultura e do Abastecimento; Embrapa. Comunicação para Transferência de Tecnologia. 2000. cap. 2, p. 13-27 (Frutas do Brasil, $5)$.

GORGATTI NETTO, A.; CARVALHO, V. D. de; BOTREL, N.; BLEINROTH, E. W.; MATALLO, M.; GARCIA, A. E.;ARDITO, E. F. G.; GARCIA, E. E. R.; BORDIN, M. R. Abacaxi para exportação: procedimentos de colheita e pós-colheita. Brasília: EMBRAPA-SPI, 1996. 41p. (Série Publicações Técnicas FRUPEX, 23).

MILLER, G. L. Use of dinitrosalicylic acid reagent for determination of reducing sugars. Analytical Chemistry, Washington, v.31, n3, p.426$428,1959$.

PICO, D.; PÓLIT, P. Efecto del uso de recubrimientos y fundas plásticas sobre a calidad de piña durante um almacenamento que simula um proceso de exportação. Revista Iberoamericana de Tecnología Postcosecha, México, v. 2, n.2, p.130-138, 2000.

REINHARDT, D. H. R. C.; SOUZA, J. da S. The pineapple industry in Brazil. Acta Horticulturae Wageningen, v.529, p. 57-71, 2000.

SALUNKHE, D. K.; DESAI, B. B. Postharvest biotechnology of fruits. Boca Raton: CRC Press, 1984. v. 2, 194p.

SARANTOPOULUS, C. I. G. L. Embalagens para vegetais minimamente processados-Fresh-cut. In: SEMINÁRIO SOBRE HORTALIÇAS MINIMAMENTE PROCESSADAS, 1999, Piracicaba. Palestra... Piracicaba: ESALQ-USP, 1999. 6p. Apostila.

SARZI, B. Conservação de abacaxi e mamão minimamente processados: associação entre preparo, a embalagem e a temperatura de armazenamento. 2002. 100f. Dissertação (Mestrado em Produção Vegetal) - Faculdade de Ciências Agrárias e Veterinárias, Universidade Estadual Paulista, Jaboticabal, 2002.

SILVA, M.A. Fisiologia pós-colheita de abacaxi cvs. Pérola e Smooth Cayenne. 1980, 203f. Dissertação (Mestrado em Engenharia Agrícola) - FEAGRI, Universidade de Campinas, Campinas, 1980.

THÉ, P. M. P.; CARVALHO, V. D. de.; ABREU, C. M. P. de.; NUNES, R. de P.; PINTO, N. A V. D. Efeito da temperatura de armazenamento e do estádio de maturação sobre a composição química do abacaxi cv. Smooth Cayenne L. Ciências Agrotécnicas, Lavras, v.25, n.2, p.356363, 2001.

WOLF,A.B.; MACRAE, E.A.; SPOONER, K.J.; REDEWELL, R.J. Changes to physical properties of the cell wall and polyuronides in response to heat treatment of 'Fuyu' persimmon that alleviate chilling injury. Journal of American Society for Horticultural Science, Alexandria, v.122, p.698-702, 1997. 